\title{
Investigating dental caries rates amongst sentenced prisoners in KwaZulu-Natal, South Africa
}

SADJ April 2020, Vol. 75 No. 3 p 137 - p141

M Radebe', S Singh ${ }^{2}$

\section{ABSTRACT}

\section{Objective}

To establish the prevalence of dental caries amongst KZN sentenced prisoners.

\section{Methods \\ The frequency and distribution of dental caries were assessed using the DMFT Index (Decayed, Filled, Missing teeth) in non-invasive dental clinical examinations of a sample of sentenced prisoners $(n=373)$ randomly selec- ted from amongst inmates at nine correctional centres located within the eleven health districts in KwaZulu- Natal, South Africa. The recorded data were analysed using SPSS version 24.}

\section{Results}

The mean DMFT scores were: overall $5.92(+4.65) ; 18$ to 29 years: $4.14( \pm 3.49) ; 30$ to 39 years: $6.17( \pm 4.19)$; 40 to 49 years: $9.08( \pm 5.38)$; older than 50 years: $11.31(+6.30)$.

A statistically significant relationship was found between DMFT and age ( $p$-value: 0.000). Decayed Teeth were seen in $64.34 \%$ of participants, $71.85 \%$ recorded Missing teeth while Filled teeth (FT) were noted in only $8.04 \%$ of the study sample.

\section{Conclusion}

The results highlight the need to take into account the epidemiological trends in the rates of dental caries when planning oral health services within the KwaZulu-Natal Department of Correctional Services.

\section{Author affiliations:}

1. Mbuyiselwa Radebe: Bachelor of Dental Therapy (UDW) MBA (MANCOSA); Dip Project Management (DAMELIN), PHD Graduate: Discipline of Dentistry, School of Health Sciences, University of Kwa Zulu-Natal, Durban, South Africa. ORCID Number: 0000-0001-7201-1524

2. Shenuka Singh: B.OH (UDW), M.Sc. [DENT], PhD (UWC), PG Dip Health Res Ethics (Stell), Associate Professor, Discipline of Dentistry, School of Health Sciences, University of KwaZulu-Natal, Durban, South Africa.

ORCID Number: 0000-0003-4842-602X

Corresponding author: Mbuyiselwa Radebe

Postal address: Discipline of Dentistry, School of Health Sciences University of KwaZulu-Natal; Private Bag X54001, Durban, 4000.

Tel. no.: +27 (0)313735800

Email: mbuyiselwar@dut.ac.za

Author contributions:

1. Mbuyiselwa Radebe: Principal Researcher, write up - $75 \%$

2. Shenuka Singh: Supervisor, review and revision of write up $-25 \%$

\author{
ACRONYMS \\ DCS: Department of Correctional Services \\ KZN: KwaZulu-Natal
}

\section{INTRODUCTION}

The target groups in most oral health reviews conducted worldwide have been children, youth and adults from the general population. ${ }^{1}$ Several epidemiological studies suggest inequalities in the oral health of poor families and disadvantaged groups of individuals with 'special' healthcare needs. ${ }^{2}$ Among these are prisoners, whose health is of considerable concern especially as the number of the individuals under the jurisdiction of correction systems, including those on probation or parole, keeps on expanding..$^{1,3}$

Prisoners are more likely to have disadvantaged backgrounds or to have come from areas with increased levels of social exclusion, with a high proportion being jobless prior to sentencing. ${ }^{4}$ As a result, their oral health requirements at admission may be particularly high with a significant amount of unmet treatment needs. ${ }^{4,5}$ In addition, the facilities available in prisons may not be at an acceptable level. ${ }^{6}$

In South Africa, the Department of Correctional Services (DCS) recorded in the 2015/2016 financial report that the total inmate population was 161 984, with accommodation capacity (bed-space) of 119134 , translating to an occupancy rate of $135.96 \% .^{7}$ Of these, $72.06 \%$ were sentenced prisoners and $27.94 \%$ were as yet un-sentenced. Indubitably, correctional centres across the country are overcrowded. ${ }^{7}$ Currently, in the $\mathrm{KZN}$ region, there are 42 correctional centres which are located in eleven district municipalities.

The only available dental research involving sentenced prisoners in South Africa is a baseline survey which was conducted at Western Cape correctional centres. ${ }^{8}$ This survey aimed to collect information on oral health status, knowledge, attitudes and behaviour of inmates to oral health. ${ }^{8}$

The DMFT index recommended by the World Health Organization was created in 1938 by Klien, Palmer and Knutson to express caries experience..$^{9,10}$ The D component is for untreated caries, $M$ for missing teeth (likely due to caries) and $F$ for fillings (dental restorations 
for treatment of caries). The $T$ means index per tooth (as opposed to $\mathrm{S}$, per surface). The recommended protocol for oral health surveys is based on clinical examinations only and excludes dental radiographs. Radiographs can contribute provide additional information to epidemiologic data. ${ }^{11}$ While there have been calls for the DMF index to be replaced, this index remains the most commonly used epidemiological tool for assessing dental caries. ${ }^{12}$

To date, there has been no official information or figures reported on the prevalence of dental caries amongst inmates in KZN Correctional Service Institutions. Despite improvements in oral health, disparities still exist and are more prominent in deprived groups, particularly prisoners. $^{3}$

Compared with the general population, the oral health status of sentenced prisoners is poor. ${ }^{5}$ The current study was therefore designed to determine the oral health status and to establish the prevalence of dental caries amongst sentenced prisoners in KwaZulu-Natal correctional centres through a DMFT survey.

\section{METHODS}

The subjects in this cross-sectional descriptive study were drawn from the population of sentenced prisoners incarcerated in correctional centres located in the following KZN districts: Zululand, uMzinyathi, uThukela, uMgungundlovu, iLembe, eThekwini, Ugu, and Sisonke.

The Biomedical Research Ethics Committee of the University of KwaZulu-Natal (BE046/15) approved the study and ethical guidelines were followed to ensure confidentiality in the management of data. Gatekeeper permission was obtained from the Department of Correctional Services Research Ethics Committee. Statistical advice was sought by consultation with a statistician.

The annual DCS report for the 2015/2016 financial year indicated that the total number of sentenced prisoners in KwaZulu-Natal (inmate population) was 21 899. The number of sentenced prisoners required to offer an appropriate sample was determined using a power calculation garnered from the Business Advocacy Network, 2012

$$
\begin{aligned}
& n=\frac{N}{1+N(e) 2} \\
& n=\frac{21899}{1+21899(5 \%) 2} \\
& n=393
\end{aligned}
$$

A simple random sampling method was used to select the study participants. A total of 393 sentenced prisoners aged 18-75 years were approached and provided with clear explanations about the aim of the survey and the dental examination. Finally, 373 consented to participate in the study, giving a response rate of $95 \%$.

General demographic information data, which included variables such as gender and age of the participants, were collected by the researcher. Each participant had to undergo a non-invasive dental examination, conducted following the guidelines of the WHO (1997) oral health survey $^{10}$ to determine the prevalence of dental caries.

Each participant was requested to sit comfortably on an ordinary chair with a backrest. Visual and visuo-tactile methods were used to assess the presence of dental caries in the oral cavity. DMFT index scores were collected and recorded on a pre-designed data capturing sheet.

Radiographic examination was not undertaken. After the oral examination, participants were escorted by wardens back to their respective cells. Testing intra-examiner reliability was facilitated by repeating every fifth completed oral examination, in accord with World Health Organisation standards for oral health surveys. ${ }^{10}$

The repeated scores were compared for consistency in identifying carious lesions and in recording the data. Recorded data from the sample were transferred onto the Excel spreadsheet and then exported to the SPSS version 24. Descriptive statistics (standard deviation, frequency distribution, and measures of central tendency) were calculated for the variables age, gender, and DMFT of the prisoners.

To determine if there were statistically significant differences between variables, Pearson's chi-square tests were used and statistical significance was noted only when the $p$-value was less than 0.05 .

\section{RESULTS}

Of the 373 sentenced prisoners who consented to participate in the study, males were in the majority at $89.28 \%$ $(n=333)$ and there were 40 females $(10.72 \%)$.

Two hundred and eleven participants (56.6\%) were incarcerated in correctional centres located in urban areas, one hundred and seven participants $(28.7 \%)$ in peri-urban areas and fifty-five (14.7\%) in rural areas.

Figure 1 illustrates the distribution of sentenced prisoners according to age and gender.

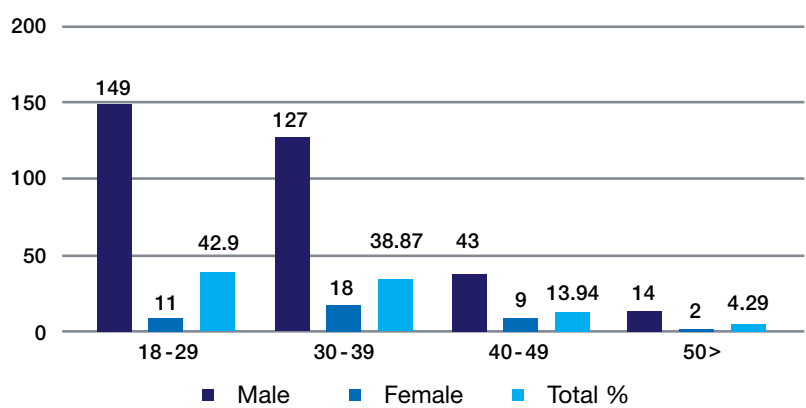

Figure 1. Distribution of sentenced prisoners by age and gender.

The distribution of the mean DMFT (Decayed, Missing, and Filled Teeth) indices among different age groups is shown in Table 1.

The mean DMFT score for the 18 to 29 years age group was $4.14(+3.49)$, for age group 30 to 39 years 
the mean was $6.17(+4.19)$; the 40 to 49 years group recorded a mean of $9.08(+5.38)$ and for participants older than 50 years the mean was $11.31(+6.30)$. The overall mean DMFT was $5.92(+4.65)$. Pearson's chi-square test indicated that there was a statistically significant relationship between DMFT and age ( $p$-value: 0.000).

Table 2 shows the prevalence of dental caries among prisoners in different age categories. Overall, the results indicated that more than two-thirds of the study population had decayed teeth $(n=240,64.34 \%)$ while missing teeth (M) were recorded in 268 participants (71.85\%). Only 30 participants $(8.04 \%)$ had any fillings (F).

The distribution of mean DMFT scores by Centres and Districts is illustrated in Table 3. In general, there was a reasonably close agreement between related Centre and District scores. The mean DMFT scores for the districts ranged from a low of 4.72 (iLembe) to a high of 7.29 (Ugu). The mean DMFT scores for Correctional Service Institutions ranged from 4.09 (Westville Medium B) to 7.83 (Westville Medium C).

The $\mathrm{M}$ component contributed most to the DMFT values followed by dental caries prevalence, the D component. The mean score of missing teeth was slightly higher amongst older age groups, whereas Decay was mostly seen amongst younger age groups.
The caries experience amongst study participants ranged from 52.50\% (Westville Medium E) to $82.71 \%$ (Port Shepstone). The overall prevalence of missing teeth varied from $55.56 \%$ (Kokstad) to $80.43 \%$ (Westville Medium C).

The lower jaw dentition of most sentenced prisoners suffered a higher incidence of untreated caries compared with the upper dentition (number of teeth affected by caries: 472, lower dentition vs 380, upper dentition).

Similarly, the lower jaw dentition had a higher number of missing teeth compared with the upper dentition (694 vs. 572). The mean DMFT was highest in the Pietermaritzburg (7.07) and Port Shepstone regions (7.29) and lowest in the Stanger region (4.72).

\section{DISCUSSION}

Participants were stratified into sub-groups, differentiated according to gender and age. Unsurprisingly, a comparative quantitative analysis of the gender composition of the study sample revealed that males were significantly over-represented amongst the sentenced prisoners.

The literature suggests that men commit a much higher percentage of serious and violent crimes, leading to their arrest and imprisonment, often for longer periods. ${ }^{13}$

\begin{tabular}{|c|c|c|c|c|c|c|c|c|c|c|c|}
\hline Age Group & \multirow{2}{*}{\multicolumn{2}{|c|}{$\begin{array}{c}\text { 18-29 years } \\
n=160\end{array}$}} & \multirow{2}{*}{\multicolumn{2}{|c|}{$\begin{array}{c}\text { 30-39 years } \\
n=145\end{array}$}} & \multirow{2}{*}{\multicolumn{2}{|c|}{$\begin{array}{c}\text { 40-49 years } \\
n=52\end{array}$}} & \multirow{2}{*}{\multicolumn{2}{|c|}{$\begin{array}{c}50>\text { years } \\
n=16\end{array}$}} & \multirow{2}{*}{\multicolumn{2}{|c|}{$\begin{array}{c}\text { Total } \\
n=373\end{array}$}} & \multirow{3}{*}{$p$-Value } \\
\hline \multirow[t]{2}{*}{ No: } & & & & & & & & & & & \\
\hline & Mean & SD & Mean & SD & Mean & SD & Mean & SD & Mean & SD & \\
\hline DMFT & 4.14 & 3.49 & 6.17 & 4.19 & 9.08 & 5.38 & 11.31 & 6.30 & 5.92 & 4.65 & 0.000 \\
\hline D & 3.66 & 2.32 & 3.97 & 2.57 & 4.06 & 2.78 & 3.94 & 2.79 & 3.85 & 2.50 & 0.211 \\
\hline M & 1.89 & 2.24 & 3.53 & 3.20 & 6.10 & 5.64 & 8.44 & 6.95 & 3.39 & 3.94 & 0.000 \\
\hline $\mathbf{F}$ & 0.14 & 0.68 & 0.30 & 1.26 & 0.54 & 1.74 & 0.50 & 1.41 & 0.27 & 1.15 & 0.420 \\
\hline
\end{tabular}

\begin{tabular}{|c|c|c|c|c|c|c|c|c|c|c|}
\hline Variables & \multicolumn{2}{|c|}{$18-29$ years } & \multicolumn{2}{|c|}{$30-39$ years } & \multicolumn{2}{|c|}{$40-49$ years } & \multicolumn{2}{|c|}{$50>$ years } & \multicolumn{2}{|c|}{ Total } \\
\hline \multirow[t]{2}{*}{ No: } & \multicolumn{2}{|c|}{$n=160$} & \multicolumn{2}{|c|}{$n=145$} & \multicolumn{2}{|c|}{$n=52$} & \multicolumn{2}{|c|}{$n=16$} & \multicolumn{2}{|c|}{$n=373$} \\
\hline & $n$ & $\%$ & $n$ & $\%$ & $n$ & $\%$ & $n$ & $\%$ & $n$ & $\%$ \\
\hline Decayed Teeth & 102 & 63.75 & 96 & 66,21 & 32 & 61,54 & 10 & 62,5 & 240 & 64,34 \\
\hline Missing Teeth & 88 & 55 & 119 & 82.07 & 45 & 86.54 & 16 & 100 & 268 & 71.85 \\
\hline Filled Teeth & 8 & 5 & 12 & 8.28 & 8 & 15.38 & 2 & 12.50 & 30 & 8.04 \\
\hline
\end{tabular}

\begin{tabular}{|c|c|c|c|c|}
\hline District & Correctional Centres & Rural/Peri-Urban/ Urban & $\begin{array}{c}\text { Mean } \\
\text { DMFT (Centre) }\end{array}$ & $\begin{array}{c}\text { Mean } \\
\text { DMFT (District) }\end{array}$ \\
\hline Uthukela & Ladysmith & PU & 5.83 & 5.83 \\
\hline Umzinyathi & Pomeroy & $\mathrm{R}$ & 5.97 & 5.97 \\
\hline \multirow[t]{2}{*}{ Umngungundlovu } & Pietermaritzurg & $U$ & 6.82 & \multirow[t]{2}{*}{7.07} \\
\hline & New Hanover & $\mathrm{R}$ & 7.31 & \\
\hline \multirow[t]{4}{*}{ eThekwini } & Westville Medium B & $U$ & 4.90 & \multirow[t]{4}{*}{5.66} \\
\hline & Westville Medium C & $U$ & 7.83 & \\
\hline & Westville Medium D & $U$ & 4.09 & \\
\hline & Westville Medium E & $U$ & 5.83 & \\
\hline Sisonke & Kokstad & PU & 5.11 & 5.11 \\
\hline Zululand & Vryheid & PU & 5.91 & 5.91 \\
\hline Ugu & Port Shepstone & $U$ & 7.29 & 7.29 \\
\hline iLembe & Stanger & PU & 4.72 & 4.72 \\
\hline
\end{tabular}


Analysis of the DMFT components reflected the generational differences, indicating a steeper gradient in older age groups particularly in the $M$ (missing teeth) component. This finding could indicate that dental extractions were the only clinical procedure performed in these institutions.

Supporting this view, Singh et al. ${ }^{14}$ asserted that in KwaZulu-Natal the focus is currently on curative rather than preventive services, with a priority not given to oral health in budget allocations. ${ }^{14}$ These high levels of missing teeth require further research to determine the need for oral rehabilitation.

The present study recorded a comparatively low prevalence of DMFT in contrast with the study conducted in Western Cape correctional institutions. ${ }^{8}$ Many factors may have contributed to the differences in the severity of dental caries between the Western Cape and KwaZuluNatal, but it is suggested that the different fluoride concentrations in the potable water of these provinces may be a confounding variable which could have influenced the disparities in DMFT prevalence.

The levels of fluoride in potable water in the Western Cape are much lower than the optimal level required to prevent the formation of cavities, ${ }^{15}$ whilst KwaZuluNatal has generally higher fluoride concentrations in drinking water, possibly resulting in some protection against decay. ${ }^{16}$ Clear evidence exists that fluoride toothpaste application is efficacious in preventing caries. ${ }^{17}$

Perversely, South African sentenced prisoners are permitted to receive only one tube of (fluoridated) toothpaste for a two-month period. ${ }^{18}$ This is a clear indication that access to materials for dental care in correctional centres is limited. ${ }^{19}$ A scarcity of self-care items such as toothbrushes and dental floss limits preventive measures and could lead to tooth extractions as being the more viable option for pain relief. ${ }^{20,21}$

\section{Limitations}

Although findings from this study have important practical and political implications, several limitations should be noted, the primary limitation being the cross-sectional design.

The current study provided a snapshot of dental caries prevalence amongst sentenced prisoners in KZN correctional institutions. As a result, it was difficult to draw any causal inference.

Another limitation identified in this study was a lack of dual-diagnosis in the identification of dental caries. Therefore, there was a possibility of under-diagnosis of proximal lesions. Despite these limitations, the current findings serve as baseline data for sentenced prisoners in the correctional institutions in KZN. This survey demonstrated that dental caries rates were high in the study population. The findings of this study could prove valuable to oral health professionals and to the Department of Correctional Services for developing effective oral health and oral care programmes for incarcerated populations.

\section{CONCLUSION}

Given the high prevalence of dental caries in sentenced prisoners, there is need to review the current oral health services for this population to ensure that preventive programmes are prioritized in oral health planning for correctional service institutions.

\section{Declaration}

The authors declare that there is no conflict of interest regarding the publication of this paper.

\section{Acknowledgments}

The authors would like to express their sincere appre-ciation and gratitude to the Department of Correctional Services for their assistance during this research project and would like to thank all the participants in the study who showed much enthusiasm and co-operation.

\section{References}

1. Nobile CGA, Fortunato L, Pavia M, Catanzaro IF. Oral health status of male prisoners in Italy. International Dental Journal 2007. 57: 27-35.

2. Gibson G, Rosenheck R, Tullner JB, Grimes RM, Seibyl $\mathrm{CL}$, Rivera-Torres A. A national survey of the oral health status of homeless veterans. J Public Health Dent. 2003; 63: 30-7.

3. Jones CM, Woods K, Neville J, Whittle JG. The dental health of prisoners in the North West England in 2000: Literature review and dental health survey results. Community Dental Health 2005; 22: 113-7.

4. George B. Prosthetic status and treatment needs of prisoners in Central Prison, Chennai. The Journal of the Indian Prosthodontic Society. 2013; 13(3): 265-8.

5. Treadwell HM, Formicola AJ. Improving the oral health of prisoners to improve overall health and well being. American J Public Health 2005; 10:1677-8.

6. Heng CK, Morse DE. Dental caries experience of female inmates. J Public Health Dent. 2002; 62: 57-61.

7. DCS. Annual Report 2015/2016 Financial Year. Depart ment Correctional Services, Republic of South Africa. 2016.

8. Naidoo S, Yengopal V, Cohen B. A baseline: Oral health status of prisoners in Western Cape. SADJ. 2005; 60: 24-7.

9. Mehta A. Comprehensive review of caries assessment systems developed over the last decades. RSBO 2012; 9(3): 316-21.

10. WHO. Oral Health Survey: Basic Methods. World Health Organisation. 1997.

11. Eslamipour F, Borzabadi-Farahani A, Asgari I. The relationship between aging and oral health inequalities assessed by the DMFT index. European Journal of Paediatric Dentistry 2010;11 (4):193-9.

12. Broadbent JM, Thomson WM. For debate: problems with the DMF index pertinent to dental caries data analysis. Community Dentistry and Oral Epidemiology 2005; 33(6): 400-9.

13. Loesche D. The prison gender gap. Statistica.com/chart/ $11573 /$ Gender of inmates in US Federal prisons and general population. October 23, 2017.

14. Singh S, Myburgh NG, Lalloo R. Policy analysis of oral health promotion in South Africa. Global Health Promotion. 2010; 17(1): 16-24.

15. Mohamed N. Fluoride: to supplement or not. Health 24. Oral Health. 2016. health 24.com/medical/oral health/ dental care/Fluoride-to-supplement-or-not-2012721. 
16. Ramjatan A, Ahmed F, Hodgson K, Simpson D, Quinn N. The Potential Impacts of Water Fluoridation: A Case Study of the Umgeni Water Operational Area, KwaZulu-Natal. WISA 2000 ; 28 May - 1 June 2000; Biennial Conference, Sun City, South Africa 2000.

17. Marinho VC, Higgins JP, Sheiham A, Logan S. Fluoride toothpastes for preventing dental caries in children and adolescents. Cochrane Database Syst Rev. 2003.

18. SAHRC. The National Prisons Project of the South African Human Rights Commission. South Africa: SAHRC; 1998.

19. Harvey S, Anderson B, Cantore S, King E, Malik F, Bedi R. Reforming prison dental services in England. A guide to good practice. Health Education. 2005; 64 (4): 1-39.

20. Rodrigues ISAA, Silveira ITdM, Pinto MSdA, Xavier AFC, de Oliveira TBS, de Paiva SM, et al. Locked Mouths: Tooth Loss in a Women's Prison in Northeastern Brazil. The Scientific World Journal. Volume 2014 article id 587469 https://doi.org/10.1155/2014/587469.

21. WHO. The World Health Report 2008. Primary health care - now more than ever. Geneva, Switzerland: World Health Organization. 2008.

\section{Do the CPD questionnaire on page 161}

The Continuous Professional Development (CPD) section provides for twenty general questions and five ethics questions. The section provides members with a valuable source of CPD points whilst also achieving the objective of CPD, to assure continuing education. The importance of continuing professional development should not be underestimated, it is a career-long obligation for practicing professionals.

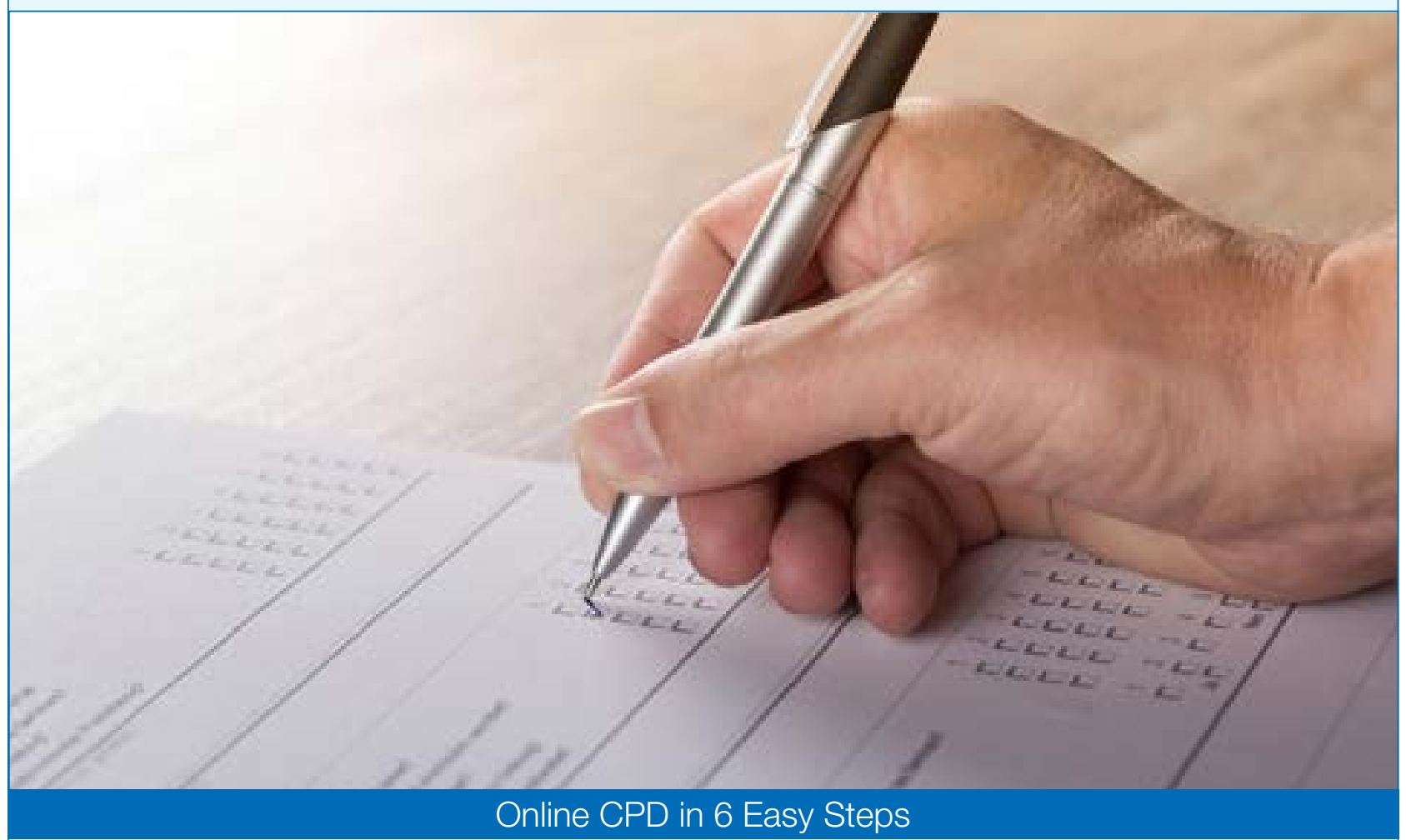

1 Go to the SADA website www.sada.co.za.

2 Log into the 'member only' section with your unique SADA username and password.

3 Select the CPD navigation tab.

4 Select the questionnaire that you wish to complete.

5 Enter your multiple choice answers. Please note that you have two attempts to obtain at least $70 \%$.

6 View and print your CPD certificate. 